\title{
PENGARUH KONSENTRASI ROOTONE-F DAN PANJANG SETEK PADA PERTUMBUHAN Rhododendron mucronatum G. Don. var. phoeniceum
}

\author{
(EFFECT OF ROOTONE-F CONCENTRATIONS AND LENGTH OF CUTTINGS ON \\ GROWTH OF Rhododendron mucronatum G. Don. var. phoeniceum)
}

\author{
DYAN M.S. PUTRI \\ Balai Konservasi Tumbuhan Kebun Raya "Eka Karya" Bali - LIPI, \\ Candikuning, Baturiti, Tabanan, Bali 82191 \\ Email: dyan.ari79@gmail.com
}

Diterima 9 April 2017. Disetujui 20 Juni 2017

\section{INTISARI}

Rhododendron mucronatum G. Don. var. phoeniceum merupakan salah satu jenis tanaman hias yang mempunyai nilai ekonomi dan estetika tinggi. Permasalahan yang sering dialami dalam perbanyakan tanaman ini adalah sulitnya stek berakar dan terbatasnya ketersediaan bibit di pasaran. Penelitian bertujuan untuk mengetahui pengaruh zat pengatur tumbuh tanaman (Rootone-F) dan panjang stek batang pada pertumbuhan R. mucronatum G. Don. var. phoeniceum. Rancangan yang digunakan dalam penelitian ini adalah rancangan acak kelompok faktorial; dua faktor dengan tiga ulangan. Faktor pertama adalah konsentrasi Rootone-F (o, 150, 300, dan 450 $\mathrm{mg} / \mathrm{L})$ dan faktor kedua adalah panjang stek batang $(15 ; 25$; dan $35 \mathrm{~cm})$. Hasil penelitian menunjukkan bahwa konsentrasi Rootone-F dan panjang stek berpengaruh sangat nyata $(\alpha<0,01)$ terhadap jumlah daun, jumlah akar dan tinggi bibit dan penggunaan panjang stek berpengaruh sangat nyata $(\alpha<0,05)$ terhadap tinggi bibit. Konsentrasi Rootone-F optimum untuk pertumbuhan stek pucuk $R$. mucronatum G. Don. var. phoeniceum. yaitu $450 \mathrm{mg} / \mathrm{L}$ yang ditunjukkan oleh nilai rerata jumlah daun sebanyak 8,8 helai, nilai rerata jumlah akar sebanyak 9,6 akar dan nilai rerata tinggi bibit 0,90 cm bila dibandingkan dengan kontrol. Panjang stek $35 \mathrm{~cm}$ memberikan pertumbuhan bibit $R$. mucronatum G. Don. var. phoeniceum tertinggi yang ditunjukkan oleh nilai rerata jumlah daun sebanyak 6,6 helai, nilai rerata jumlah akar sebanyak 8,6 buah dan nilai rerata pertambahan tinggi bibit $0,88 \mathrm{~cm}$ bila dibandingkan panjang stek $15 \mathrm{~cm}$ dan $25 \mathrm{~cm}$.

Kata kunci: Pembiakan vegetatif; Panjang stek; Zat pengatur tumbuh

\begin{abstract}
Rhododendron mucronatum G. Don. var. phoeniceum is one of ornamental plants that have high economic value and aesthetics. Problems that often experienced in propagation this plant are difficulties in producing roots on cutting and limited availability of seeds on the market. This study aims to determine the effect of plant growth regulators (Rootone-F) and length of stem cuttings on the growth of $R$. mucronatum G. Don. var. phoeniceum. This study employed completely randomized block design with two factors and three replications. The first factor is concentration of Rootone-F $(0,150,300$, and $450 \mathrm{mg} / \mathrm{L})$ and the second factor is length of stem cuttings $(15 ; 25$; and $35 \mathrm{~cm}$ ). The results showed that the concentration of Rootone-F and cuttings length has significant effect ( $\alpha$ $<0.01)$ to number of leaves, roots and seedling height; and cuttings length was highly significant $(\alpha<0.05)$ to the seedling height. Rootone-F optimum concentration for the cuttings growth of shoot $R$. mucronatum G. Don. var. phoeniceum is $450 \mathrm{mg} / \mathrm{L}$ which is indicated by the average value of the number of leaves as much as 8.8 leaves, the average value of the number of roots as much as 9.6 and a mean value of $0.90 \mathrm{~cm}$ tall seedlings when compared with controls. Cuttings with $35 \mathrm{~cm}$ long provide seed growth $R$. mucronatum G. Don. var. phoeniceum. The highest indicated by the mean number of leaves as much as 6.6 leaves, the average value of the number of roots of 8.6 and a mean value of $0.88 \mathrm{~cm}$ additional seedlings height compared to cuttings at $15 \mathrm{~cm}$ length and $25 \mathrm{~cm}$.
\end{abstract}

Keywords: Cutting length; Plant growth regulator; vegetative propagation

\section{PENDAHULUAN}

Di daerah Malesiana, Rhododendron telah banyak dimanfaatkan sebagai tanaman hias dan merupakan komoditi hortikultura yang penting; baik itu jenis ataupun hibridisasi. Menurut beberapa penelitian yang telah dilakukan di Indonesia, potensi lain dari Rhododendron adalah sebagai antibakterial ( $R$. kanori dan $R$. macgregoriae) dan penghasil senyawa flavonoid ( $R$. javanicum dan $R$. macgregoriae). Rhododendron mucronatum varietas 
juga bermanfaat untuk menghilangkan sakit demam dan perangsang kelenjar (Anonymous, 1966; Heyne, 1987; Waldan, 2007).

Secara umum Rhododendron dapat diperbanyak secara generatif maupun vegetatif. Selama ini perbanyakan Rhododendron lebih banyak dilakukan secara vegetatif karena perbanyakan secara generatif melalui biji memerlukan waktu yang relatif lebih lama dan seringkali tanaman tersebut sulit/tidak menghasilkan biji. Perbanyakan secara vegetatif relatif lebih mudah untuk dilakukan bila dibandingkan secara generatif. Kelebihan perbanyakan secara vegetatif antara lain tanaman baru yang dihasilkan sama dengan tanaman induk, memiliki umur yang seragam, tahan terhadap penyakit dan dalam waktu yang relatif singkat dapat dihasilkan tanaman baru dalam jumlah banyak. Perbanyakan secara vegetatif dapat dilakukan dengan stek, yaitu pemotongan/pemisahan bagian tumbuhan agar bagian tanaman tersebut membentuk akar dan menjadi individu baru (Putri dan Sudiatna, 2009).

Perbanyakan tanaman Rhododendron mucronatum G. Don. var. phoeniceum dilakukan dengan setek batang. Masalah yang sering timbul pada perbanyakan vegetatif tanaman berkayu melalui setek adalah sulitnya bahan tanaman membentuk akar (Tebbit, 2005 dan Mashudi, 2013). Hasil penelitian menunjukkan bahwa zat pengatur tumbuh (ZPT) IBA dengan konsentrasi $400 \mathrm{mg} / \mathrm{l}$ dapat merangsang pertumbuhan akar setek bambu petung (Sumiasri \& Indarto 2001). ZPT yang dipergunakan untuk meningkatkan perakaran setek antara lain Indole Acetic Acid (IAA), Indole Butiric Acid (IBA), Naphthalene Aetic Acid (NAA), dan Rootone-F. Rootone-F merupakan ZPT sintetik yang bahan aktifnya merupakan gabungan dari IBA dan NAA yang sangat efektif merangsang pertunasan dan pertumbuhan perakaran setek (Kosasih \& Rochayat 2000, Arinasa et al. 2015).

Pertumbuhan setek dipengaruhi oleh ukuran/panjang setek. Panjang setek menentukan jumlah cadangan makanan yang terkandung dalam setek, serta menunjukkan persediaan energi yang diperlukan dalam pertumbuhan akar dan tunas lebih banyak. Penggunaan panjang setek dengan ukuran 15-30 cm (2 ruas) lebih efisien dalam penggunaan bahan material setek karena secara morfologi perawakan tanaman tingginya bisa mencapai 1,5-2 m (Santoso et al. 2008). Hasil penelitian Putri dan Sudiatna, 2009 menyebutkan bahwa penggunaan Rootone-F $200 \mathrm{mg} / \mathrm{l}$ pada Rhododendron javanium Benn. telah memberikan hasil yang optimal pada pertumbuhan tunas baru dan pada penelitian bambu petung hitam menggunakan Rootone-F menunjukkan bahwa penggunaan konsentrasi $400 \mathrm{mg} / \mathrm{l}$ memberikan hasil yang paling optimal untuk pertumbuhan panjang akar dan jumlah daun (Arinasa et al. 2015). Penelitian tentang pengaruh konsentrasi ZPT dan panjang setek terhadap pertumbuhan bibit $R$. mucronatum G. Don. var. phoeniceum masih sangat terbatas sehingga penggunaan rujukan pustaka juga sangat minim. Tujuan penelitian adalah untuk mengetahui pengaruh konsentrasi Rootone-F dan panjang setek serta interaksinya terhadap pertumbuhan bibit $R$. mucronatum G. Don. var. phoeniceum.

\section{MATERI DAN METODE}

\section{Waktu dan Tempat}

Penelitian ini dilakukan selama 3 bulan dari tanggal April - Juni 2013 di Pembibitan Balai Konservasi Tumbuhan Kebun Raya 'Eka Karya' Bali - LIPI pada ketinggian tempat $1.250 \mathrm{~m}$ dpl. dengan kisaran suhu udara $11^{\circ} \mathrm{C}-26^{\circ} \mathrm{C}$ dan kelembaban udara berkisar antara $30-80 \%$.

Bahan dan alat yang dipergunakan meliputi ZPT Rootone-F, stek batang $R$. mucronatum G. Don. var. phoeniceum (Gambar 1.), alkohol 70\%, polibag diameter $10 \mathrm{~cm}$. Penelitian dirancang dalam bentuk rancangan acak kelompok (RAK). Perlakuan disusun secara faktorial dengan tiga kali ulangan. Faktor pertama adalah konsentrasi Rootone-F dengan empat taraf yaitu: ro (konsentrasi Rootone-F o mg/L (kontrol)); r1 (konsentrasi Rootone-F $150 \mathrm{mg} / \mathrm{L}$ ); r2 (konsentrasi Rootone-F $300 \mathrm{mg} / \mathrm{L}$ ); dan r3 (konsentrasi Rootone-F $450 \mathrm{mg} / \mathrm{L}$ ). Faktor kedua adalah panjang stek R. mucronatum G. Don. var. phoeniceum dengan tiga taraf yaitu: p1 (stek batang panjang $15 \mathrm{~cm}$ dengan satu ruas/buku); p2 (stek batang panjang $25 \mathrm{~cm}$ dengan satu ruas/buku); dan p3 (stek batang panjang $35 \mathrm{~cm}$ dengan satu ruas/buku).

Setiap unit perlakuan terdiri atas lima pot tanaman dan pada setiap pot ditanam satu setek batang. Penempatan pot perlakuan dilakukan secara acak. Masing-masing konsentrasi Rootone-F dilarutkan dalam $20 \mathrm{ml}$ alkohol 70\%. Setelah bubuk ini larut secara merata, kemudian ditambahkan air sehingga masing-masing menjadi 1 li-

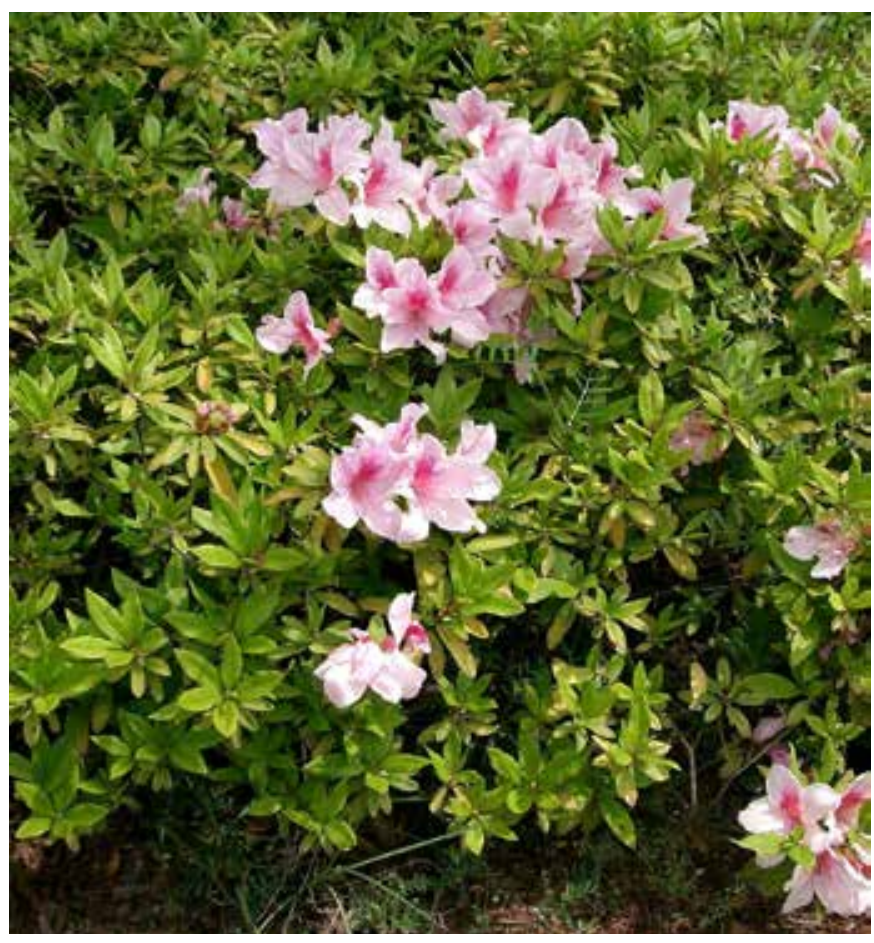

Gambar 1. R. mucronatum G. Don. var. phoeniceum 
ter larutan. Setek batang yang digunakan adalah setek yang telah direndam larutan Rootone F dengan berbagai konsentrasi selama satu jam; jumlah daun yang seragam sekitar $5-7$ helai daun, ditanam pada pot berdiameter $10 \mathrm{~cm}$ dengan media akar kadaka:pakis:arang dengan perbandingan 2:2:1 (Putri dan Sudiatna, 2009).

Pengamatan pertumbuhan tanaman dilakukan dengan cara mencatat, menghitung, dan mengukur tinggi bibit, jumlah daun, dan jumlah akar per bibit pada saat bibit berumur 90 hari. Pengamatan pertambahan tinggi bibit tanaman dilakukan dengan cara mengukur tinggi awal setek tanaman sebelum dilakukan penanaman. Kemudian pada hari terakhir pengamatan diukur lagi pertambahan panjang setek, dan dicari selisih tinggi batang setek akhir dengan setek awal sehingga diperoleh pertambahan tinggi bibit selama waktu penelitian dilakukan. Pengamatan pertambahan jumlah daun dihitung berdasarkan pertambahan jumlah daun baru yang tumbuh sejak dilakukan penanaman awal sampai pada hari terakhir pengamatan. Pengamatan jumlah akar dilakukan dengan menghitung jumlah akar yang terbentuk pada akhir pengamatan.

Data yang diperoleh kemudian dianalisis dengan metode sidik ragam sesuai dengan rancangan yang digunakan untuk mengetahui tingkat signifikansi antara konsentrasi Rootone-F dan panjang setek terhadap pertumbuhan dan bentuk hubungan antara perlakuan (panjang setek awal dan konsentrasi Rootone-F) pada bibit $R$. mucronatum G. Don. var. phoeniceum. Apabila sidik ragam menunjukkan pengaruh yang nyata maka dilanjutkan uji beda nilai rerata dengan metode uji LSD.

\section{HASIL}

Hasil analisis statistik menunjukkan bahwa terjadi korelasi antara konsentrasi Rootone-F dan panjang setek berpengaruh sangat nyata $(\alpha<0,01)$ terhadap jumlah daun, jumlah akar dan tinggi bibit dan penggunaan panjang setek berpengaruh sangat nyata $(\alpha<0,05)$ terhadap tinggi bibit (Tabel 1.). Hal ini dikarenakan konsentrasi yang digunakan (o-450 $\mathrm{mg} / \mathrm{l}$ ) dan panjang setek yang digunakan telah mampu meningkatkan pertumbuhan dan memberikan cadangan makanan yang tersimpan untuk pertumbuhan bibit $R$. mucronatum G. Don. var. phoeniceum.

\section{PEMBAHASAN}

Konsentrasi Rootone-F berpengaruh nyata $(\alpha<0,05)$ terhadap jumlah daun, jumlah akar, tinggi bibit dengan nilai rerata terendah pada konsentrasi o $\mathrm{mg} / \mathrm{L}$ (kontrol) dan tertinggi pada konsentrasi $450 \mathrm{mg} / \mathrm{L}$. Pada rerata jumlah daun, konsentrasi Rootone-F o mg/L, $150 \mathrm{mg} / \mathrm{L}, 300 \mathrm{mg} / \mathrm{L}$ dan $450 \mathrm{mg} / \mathrm{L}$ berbeda nyata $(\alpha$ $<0,05$ ) dengan nilai berkisar antara 6-8,8 helai daun namun pada konsentrasi Rootone-F $300 \mathrm{mg} / \mathrm{L}$ dan 450 $\mathrm{mg} / \mathrm{L}$ tidak berbeda nyata $(\alpha<0,05)$. Pada rerata jum-
Tabel 1. Signifikansi Pengaruh Konsentrasi Rootone-F dan Panjang Stek terhadap Jumlah Daun, Jumlah Akar dan Pertambahan Tinggi Bibit $R$. mucronatum G. Don. var. phoeniceum

\begin{tabular}{|c|c|c|c|}
\hline \multirow[b]{2}{*}{ Variabel } & \multicolumn{3}{|c|}{ Perlakuan } \\
\hline & $\begin{array}{l}\text { Konsentrasi } \\
\text { Rootone-F } \\
(\mathrm{mg} / \mathrm{L})\end{array}$ & $\begin{array}{c}\text { Panjang } \\
\text { Setek }(\mathrm{cm})\end{array}$ & $\begin{array}{l}\text { Signifikansi Konsentrasi } \\
\text { Rootone-F (mg/L) dan } \\
\text { Panjang Setek (cm) }\end{array}$ \\
\hline Jumlah Daun & $* *$ & * & $\mathrm{X}$ \\
\hline Jumlah Akar & $* *$ & $\mathrm{x}$ & $\mathrm{X}$ \\
\hline Tinggi Bibit & $* *$ & $* *$ & $* *$ \\
\hline
\end{tabular}

* = berpengaruh nyata $(\alpha<0,05)$

** = berpengaruh sangat nyata $(\alpha<0,01)$

$\mathrm{x}=$ berpengaruh tidak nyata $(\alpha \geq 0,05)$

Tabel 2. Pengaruh Konsentrasi Rootone -F terhadap Jumlah Daun, Jumlah Akar dan Pertambahan Tinggi Bibit $R$. mucronatum G. Don. var. phoeniceum

\begin{tabular}{cccc}
\hline Perlakuan & $\begin{array}{c}\text { Jumlah Daun } \\
\text { (helai) }\end{array}$ & $\begin{array}{c}\text { Jumlah Akar } \\
\text { (buah) }\end{array}$ & Tinggi Bibit (cm) \\
\hline \multirow{4}{c}{ Konsentrasi Rootone-F (mg/L) } \\
o (kontrol) & $6 \mathrm{a}$ & $7,8 \mathrm{a}$ & $0,42 \mathrm{a}$ \\
150 & $7 \mathrm{~b}$ & $8,6 \mathrm{ab}$ & $0,56 \mathrm{~b}$ \\
300 & $8,4 \mathrm{c}$ & $9,2 \mathrm{~b}$ & $0,72 \mathrm{c}$ \\
450 & $8,8 \mathrm{c}$ & $9,6 \mathrm{~b}$ & $0,9 \mathrm{od}$ \\
& Panjang Setek (cm) \\
15 & $5,8 \mathrm{a}$ & $8,0 \mathrm{a}$ & $0,40 \mathrm{a}$ \\
25 & $6,4 \mathrm{ab}$ & $8,0 \mathrm{a}$ & $0,64 \mathrm{~b}$ \\
35 & $6,6 \mathrm{~b}$ & $8,6 \mathrm{a}$ & $0,88 \mathrm{c}$
\end{tabular}

Tanda huruf kecil yang berbeda di belakang angka pada masing - masing kolom menunjukkan bahwa nilai berbeda nyata berdasarkan uji BNJ, $\alpha=0,05$

lah akar, konsentrasi Rootone-F o mg/L dengan nilai 7,8 buah, namun tidak berbeda nyata $(\alpha<0,05)$ pada konsentrasi Rootone-F $150 \mathrm{mg} / \mathrm{L}, 300 \mathrm{mg} / \mathrm{L}$ dan 450 $\mathrm{mg} / \mathrm{L}$. Pada rerata tinggi bibit berbeda nyata berbeda nyata $(\alpha<0,05)$ pada seluruh konsentrasi Rootone-F dengan nilai berkisar $0,42-0,90 \mathrm{~cm}$ (Tabel 2.).

Hal ini disebabkan karena konsentrasi Rootone-F yang diberikan dapat memacu pertumbuhan akar dan tunas setek sehingga pertumbuhan setek menjadi lebih baik. Pada umumnya campuran dari beberapa zat pengatur tumbuh lebih efektif daripada zat pengatur tumbuh tunggal, seperti pada zat pengatur tumbuh Rootone-F. Zat ini mengandung formulasi dari Napthalene Acetic Acid (NAA), Indole Acetic Acid (IAA) dan IBA yang berbentuk tepung berwarna putih. Pada Rootone-F IAA berperan didalam mempercepat pemanjangan sel-sel pada jaringan meristem akar tanaman. IBA dan NAA pada mempunyai peran sangat penting dalam pembentukan akar lanjutan dari akar-akar lateral yaitu pada pembentukan rambut-rambut akar (Nurasari, et al. 2012 dan Modeste, et al. 2013). Rootone-F mengandung IBA dan NAA juga berfungsi sebagai stimulator pembelahan sel sehingga lebih memungkinkan terbentuknya sistem perakaran yang dapat meningkatkan aktivitas fisiologis tanaman. Untari \& Puspitaningtyas (2006) menyatakan bahwa setek yang mendapat perlakuan campuran zat tumbuh IBA dan NAA atau IAA dan NAA pada umumnya didapatkan pertumbuhan akar yang lebih banyak dari 
masing-masing komponen dengan kadar yang sama.

Sedangkan untuk panjang setek berpengaruh nyata $(\alpha<0,05)$ terhadap tinggi bibit namun tidak berbeda nyata $(\alpha<0,05)$ terhadap jumlah daun dan jumlah akar $(\alpha<0,05)$ dengan nilai rerata terendah pada panjang setek $15 \mathrm{~cm}$ dan tertinggi pada penggunaan setek dengan panjang $35 \mathrm{~cm}$. Hal ini dikarenakan pada panjang setek $35 \mathrm{~cm}$ tersimpan cadangan makanan yang lebih banyak dari pada bibit dengan panjang setek $15 \mathrm{~cm}$ dan $25 \mathrm{~cm}$. Pengaruh panjang setek tidak berbeda nyata $(\alpha<0,05)$ terhadap rerata jumlah daun dengan nilai terendah 5,8 $\mathrm{cm}$ pada panjang setek $15 \mathrm{~cm}$ dan nilai tertinggi $6,5 \mathrm{~cm}$ pada panjang setek $15 \mathrm{~cm}$. Pada rerata jumlah akar tidak berbeda nyata $(\alpha<0,05)$ dengan nilai berkisar 8,0-8,6 $\mathrm{cm}$, sedangkan pada rerata tinggi bibit berbeda nyata $(\alpha$ $<0,05)$ pada seluruh penggunaan panjang setek dengan nilai berkisar $0,40-0,88 \mathrm{~cm}$ (Tabel 2.).

Perlakuan panjang setek dapat meningkatkan pertumbuhan bibit $R$. mucronatum G. Don. var. phoeniceum yang ditunjukkan dengan meningkatnya jumlah daun, jumlah akar dan tinggi bibit (Tabel 2). Hal ini berarti dengan adanya sistem perakaran yang semakin baik akan dapat menyerap air dan unsur hara yang merupakan bagian terpenting dalam proses pembentukan asimilat (Mudiana \& Lugrayasa, 2001). Selain itu perlakuan panjang setek yang berbeda dapat memacu pertumbuhan akar dan tunas bibit, sehingga tunas-tunas yang tumbuh dapat segera membentuk daun dengan lebih baik (Utami et al. 2001). Menurut Hidayanto et al. (2003), bahwa panjang setek yang berbeda mempunyai kandungan faktor tumbuh yang berbeda seperti karbohidrat dan auksin yang berperan sangat penting terhadap pertumbuhan akar dan tunas. Sesuai dengan pendapat Hasanah \& Setiari (2007) bahwa panjang setek yang lebih panjang mempunyai kandungan karbohidrat dan substansi pertumbuhan seperti hormon yang lebih banyak sehingga pertumbuhan tunas/batang menjadi lebih baik. Hal ini menyebabkan panjang setek $35 \mathrm{~cm}$ lebih mampu memacu pertumbuhan akar dan tunas bibit sehingga pertumbuhan daun juga dapat berlangsung dengan baik (Hussein et al. 2005). Rofik \& Murniati (2008) dan Tukawa, et al. (2013) menyatakan bahwa pertumbuhan daun yang lebih baik berhubungan dengan peranan nitrogen yang diserap akar bagi pertumbuhan tanaman. Pertumbuhan daun yang lebih baik berperan penting dalam pembentukan hijau daun yang sangat berguna dalam proses fotosintesis (Syros et al. 2004). Selain itu untuk setek yang ukurannya lebih panjang juga memungkinkan setek dapat membentuk daun yang lebih banyak (Strzelecka, 2007).

Perlakuan konsentrasi Rootone-F dan panjang setek secara bersama-sama berpengaruh terhadap pertumbuhan bibit $R$. mucronatum G. Don. var. phoeniceum, semakin meningkat konsentrasi Rootone-F dan panjang setek yang digunakan, nilai rerata pertumbuhan bibit yang berupa jumlah daun, jumlah akar dan tinggi bibit juga semakin meningkat (Tabel 2).
Hal ini disebabkan oleh penggunaan Rootone-F sebagai zat pengatur tumbuh untuk membantu menginisiasi pertumbuhan akar dan daun serta tinggi bibit bibit $R$. mucronatum G. Don. var. phoeniceum. Kandungan bahan aktif berupa IAA, IBA, dan NAA bekerja pada jaringan meristem akar sehingga membentuk sistem perakaran baru (Kaewjampa, et al. 2013). Pertumbuhan dari setek sangat dipengaruhi oleh ketersediaan bahan makanan dari setek yang digunakan. Pemakaian panjang setek $R$. mucronatum G. Don. var. phoeniceum mulai dari $15 \mathrm{~cm}$ sampai dengan $35 \mathrm{~cm}$ ternyata mampu mendukung pertumbuhan dari bibit $R$. mucronatum G. Don. var. phoeniceum dengan cukup tersedianya bahan makanan berupa karbohidrat dan nitrogen yang terkandung dalam bahan setek. Bahan setek yang mengandung karbohidrat tinggi dan nitrogen cukup akan membentuk akar dan tunas. Menurut Harjadi (1989) terdapat beberapa faktor yang juga mempengaruhi keberhasilan setek, yaitu asal setek (posisi stek pada tanaman induk), panjang setek, dan lingkungan (media pengakaran, suhu, dan kelembaban, cahaya). Selain ketersediaan bahan makanan yang cukup untuk pertumbuhan setek, diduga keadaan lingkungan (media pengakaran, suhu dan kelembaban cahaya) dan pemilihan bahan setek yang baik juga merupakan salah satu faktor keberhasilan tumbuhnya setek (Santoso, et al. 2008). Panjang setek yang baik untuk masing-masing jenis tanaman berbeda satu dengan yang lainnya. Panjang bahan setek terkait dengan tersedianya bahan cadangan makanan. Semakin panjang stek semakin besar kesediaan bahan makanannya, begitu juga sebaliknya. Potensi cadangan makanan yang dimiliki masing-masing stek akan menentukan pertumbuhan dan perkembangan bibit ( $\mathrm{Tu}-$ kawa, et al. 2013). Hal ini terbukti dalam penelitian ini panjang setek memegang peranan dalam pertumbuhan tinggi bibit $R$. mucronatum G. Don. var. phoeniceum. Semakin panjang setek yang digunakan semakin banyak cadangan makanan yang disimpannya. Cadangan makanan ini digunakan untuk memacu pertumbuhan bibit $R$. mucronatum G. Don. var. phoeniceum.

\section{SIMPULAN}

Dari hasil penelitian ini dapat disimpulkan bahwa interaksi antara konsentrasi Rootone-F dan panjang setek berpengaruh nyata terhadap pertumbuhan bibit $R$. mucronatum G. Don. var. phoeniceum. Konsentrasi Rootone-F optimum untuk pertumbuhan setek pucuk $R$. mucronatum G. Don. var. phoeniceum. yaitu $450 \mathrm{mg} / \mathrm{L}$ yang ditunjukkan oleh nilai rerata jumlah daun sebanyak 8,8 helai, nilai rerata jumlah akar sebanyak 9,6 buah dan nilai rerata tinggi bibit $0,90 \mathrm{~cm}$ bila dibandingkan dengan kontrol. Panjang setek $35 \mathrm{~cm}$ memberikan pertumbuhan bibit $R$. mucronatum G. Don. var. phoeniceum tertinggi yang ditunjukkan oleh nilai rerata jumlah daun sebanyak 6,6 helai, nilai rerata jumlah akar sebanyak 8,6 buah dan nilai rerata tinggi bibit $0,88 \mathrm{~cm}$ bila dibandingkan panjang setek $15 \mathrm{~cm}$ dan $25 \mathrm{~m}$. 


\section{UCAPAN TERIMA KASIH}

Penulis mengucapkan terima kasih kepada temanteman di Unit Seleksi, Perbanyakan dan Re-introduksi Kebun Raya "Eka Karya" Bali - LIPI yang telah membantu terlaksananya kegiatan penelitian ini.

\section{KEPUSTAKAAN}

Anonymous. 1966. Flora Malesiana. Series I. Vol 6 (4). Rijksherbarium, Leyden. Holland.

Rofik, A dan Murniati, E 200. 'Pengaruh Perlakuan Deoperkulasi Benih dan Media Perkecambahan untuk Meningkatkan Viabilitas Benih Aren (Arenga pinnata (Wurmb.) Merr.)', Buletin Agronomi, vol. 36 (1):33-40.

Arinasa, IBK, Sujarwo, W dan Peneng, IN. 2015. 'The Effect of Rootone-F Concentrations and Type of Culm Cuttings on Growth of Black Petung Bamboo (Dendrocalamus asper (Schult.) Backer ex Heyne cv. Black)', Bamboo Journal, Japan Bamboo Society, vol. 29: 1-9.

Hasanah, FN dan Setiari, N. 2007. 'Pembentukan Akar pada Stek Batang Nilam (Pogostemon cablin Benth.) setelah Direndam IBA (indol butyric acid) pada Konsentrasi Berbeda', Buletin Anatomi dan Fisiologi, vol. 15(2):1-6.

Heyne, K. 1987. Tumbuhan Berguna Indonesia. Cetakan I. Terjemahan Badan Penelitian dan Pengembangan Kehutanan. Departemen Kehutanan RI. Jakarta.

Hidayanto, M, Nurjanah, S dan Yossita, F. 2003. 'Pengaruh Panjang Stek Akar dan Konsentrasi Natriumnitrofenol terhadap Pertumbuhan Stek Akar Sukun (Artocarpus communis F.),' Jurnal Pengkajian dan Pengembangan Teknologi Pertanian, vol. 6 (2) : 66-80.

Hussein, S, Ibrahim, R, Kiong, ALP, Fadzilah, NM dan Daud, SK. 2005. 'Multiple Shoot Formation of Important Tropical Mediclinal Plant Eurycoma Longifolia Jack', J. Biotechnol., vol. 22: 349-51.

Kosasih, AS dan Rochayat, N. 2000. 'Pengaruh Pemberian ZPT terhadap Keberhasilan Perbanyakan Jamuju (Podocarpus imbricata)', Buletin Penelitian Hutan, vol. 619: 1-11.

Mashud. 2013. 'Pengaruh Provenan dan Komposisi Media terhadap Keberhasilan Teknik Penunasan pada Setek Pucuk Pulai Darat', Jurnal Penelitian Hutan Tanaman, vol. 10 (1) : 25-32.

Mudiana, D dan Lugrayasa, IN. 2001.'Pengaruh Asal Bahan Setek dengan Perlakuan Zat Pengatur Tumbuh pada Pertumbuhan Setek Hydrangea macrophylla (Thunb.) Ser. ex DC', Prosiding Seminar Sehari: Menggali Potensi dan Meningkatkan Prospek Tanaman Hortikultura Menuju Ketahanan Pangan, Kebun Raya Bogor - LIPI. 262-268.

Putri, DMS dan Sudiatna, IN. 2009. 'Aplikasi Penggunaan ZPT pada Perbanyakan Rhododendron mucronatum
G. Don. var. phoeniceum (Batukau, Bali) secara Vegetatif', J. Biol., vol. 13 (1) : 17-20.

Strzelecka, K. 2007., 'Anatomical Structure and Adventitious Root Formation in Rhododendron ponticum L. cutting', Acta. Sci. Pol., vol. 6 (2).

Sumiasri, N dan Indarto, NS. 2001. 'Tanggap Setek Cabang Bambu Betung (Dendrocalamus asper) pada Penggunaan Berbagai Dosis Hormon IAA dan IBA', J. Nature Indonesia, vol. 3 (2:121-128.

Syros, T, Yupsanis, T, Zafiriadis, $\mathrm{H}$ dan Economou, A. 2004. 'Activity and Isoforms of Peroxidases, Lignin, and Anatomy, during Adventitious Rooting in Cuttings of Ebenus cretica L.', Plant Physiol., vol. 161: 69-77.

Tebbit, MC. 2005. Begonias, Cultivation, Identification, and Natural History, Published in Association with Brooklyn Botanic Garden, Timber Press, USA.

Untari, R dan Puspitaningtyas, DM 2006, 'Pengaruh Bahan Organik dan NAA terhadap Pertumbuhan Anggrek Hitam (Coelogyne pandurata Lindl.) dalam Kultur in vitro,' Biodiversitas, vol. 7 (3) : 344-348.

Utami, NW, Hartutiningsih-M.Siregar dan Purwantoro, RS. 2001. Perbanyakan Bibit Podocarpus spp. dengan Pemberian Zat Pengatur Tumbuh: IBA, NAA, IAA dan 2,4 D', Prosiding Seminar Sehari Menggali Potensi dan Meningkatkan Prospek Tanaman Hortikultura Menuju Ketahanan Pangan, Kebun Raya Bogor - LIPI. 274-280.

Kaewjampa , Naremol, K. Shimasaki dan N. S. Jabun. 2013. Hyaluronic Acid Can be an Alternative Plant Growth Regulator for Hybrid Cymbidium micropropagation. Academic Journals 8(28): 3731-3734.

Santoso, B.B, Hasnam, Hariyadi, S. Slamet dan S.P. Bambang. 2008. Perbanyakan Vegetatif Tanaman Jarak Pagar (Jatropha curcas L.) dengan Stek Batang: Pengaruh Panjang dan Diameter Stek. Buletin Agronomi. (36) (3) ;255-262.

Modeste, K. K. , K. K. Edmond, K. N, Gilles, G. Michel , K. Mongomake dan K. T. Hilaire. 2013. Influnce of Plant Growth Regulators on Somatic Embryogenesis Induction from Inner Teguments of Rubber (Hevea brasiliensis) seeds. Academic Journals 12(16):19721977.

Nurasari, Elda dan Djumali.2012. Respon Tanaman Jarak Pagar (Jatropha curcas L) Terhadap Lima Dosis Zat Pengatur Tumbuh (ZPT) Asam Naftalen Asetat (NAA). Agrovigor 5 (1) : 26-33.

Tukawa, N. D., E. Ratnasari , R. Wahyono. 2013. Efektivitas 6-Furfuryl Amino Purine (Kinetin) Dan 6-Benzylamino Purine (BAP) Pada Media MS Terhadap Pertumbuhan Eksplan Pucuk Mahoni (Swietenia Mahagoni) Secara In Vitro. LenteraBio 2 (1) : 63 $-67$.

Waldan, N.K. 2007. Di Balik Keindahan Rhododendron (Bisa Jadi Obat Insomnia dan Rematik). www. tabloidnova.com/articles.asp?id=11186. Di akses tanggal 20 April 2007. 